\title{
BMJ Open Clinical practice guidelines for hypertension in China: a systematic review of the methodological quality
}

\author{
Yin Chen, ${ }^{1}$ Shilian Hu, ${ }^{1,2}$ Lei Wu, ${ }^{3}$ Xiang Fang, ${ }^{4}$ Weiping $\mathrm{Xu},{ }^{1}$ Gan Shen ${ }^{1}$
}

To cite: Chen Y, Hu S, Wu L, et al. Clinical practice guidelines for hypertension in China: a systematic review of the methodological quality. BMJ Open 2015;5:e008099. doi:10.1136/bmjopen-2015008099

- Prepublication history for this paper is available online To view these files please visit the journal online (http://dx.doi.org/10.1136/ bmjopen-2015-008099).

Received 4 March 2015 Revised 30 May 2015 Accepted 25 June 2015

\section{(1) cossark}

${ }^{1}$ Anhui Evidence-based Medicine Center, Anhui Provincial Hospital, Hefei, Anhui, China

${ }^{2}$ Gerontology Institute of Anhui Province, Anhui Provincial Hospital, Hefei, Anhui, China

${ }^{3}$ Department of Neurology, Anhui Provincial Hospital, Hefei, Anhui, China

${ }^{4}$ Department of Cardiology, Anhui Provincial Hospital, Hefei, Anhui, China

Correspondence to Professor Shilian $\mathrm{Hu}$; hushilian@126.com

\section{ABSTRACT}

Objective: Clinical practice guidelines (CPGs) provide clinicians with specific recommendations for practice, but due to the increasing number of CPGs developed by diverse organisations over the past few years, there are concerns about the quality of some CPGs. This paper proposes a systematic review of the methodological quality of the CPGs for hypertension that were developed in China.

Design: A systematic review of CPGs for the management of hypertension in adult patients in China.

Data resources: Chinese electronic databases, Chinese guideline websites and Google Scholar were searched, and the reference lists of relevant publications were also screened for additional information. CPGs for the management of hypertension in adult patients were identified. The main characteristics of the CPGs were extracted, and the scaled Appraisal of Guidelines, REsearch and Evaluation II (AGREE II) domain percentages were independently evaluated by two reviewers.

Results: A total of $17 \mathrm{CPGs}$, with publication dates ranging from 2001 to 2011, were identified. There was considerable variation in the quality of the CPGs across the AGREE II domains. Overall, the domains of 'rigor of development' and 'editorial independence' were poorly addressed, with an average score of $18 \%$ and $16 \%$, respectively. Also less well addressed were the 'stakeholder involvement' and 'applicability' domains, for which the average domain scores were $28 \%$ and $20 \%$, respectively. The CPGs performance was less problematic in the domains of 'scope and purpose' and 'clarity and presentation', with a median of $41 \%$ for both. After considering the domain scores, 8 CPGs could be recommended with modification for use.

Conclusions: There is considerable room for improvement of the methodological quality of CPGs for hypertension in China. Greater efforts should to be devoted to ensure the explicit and transparent reporting of potential conflicts of interest of stakeholders, and to consider the quality of the evidence and grade recommendations in the CPG development process.

\section{INTRODUCTION}

Hypertension is an important public health challenge, and is the leading cause of death
Strengths and limitations of this study

- This is the first attempt to evaluate the methodological quality of clinical practice guidelines (CPGs) for the management of hypertension in China using the Appraisal of Guidelines, REsearch and Evaluation II (AGREE II) instrument.

- The results highlight the strengths and weaknesses of the existing CPGs, providing suggestions on how improvements can be made in the future.

- The main limitation of this study is that the methodological quality assessment was based on the information about the assessment items the individual CPGs reported, which may not actually reflect the construction process.

and disability in China. It has been estimated that one in six Chinese adults have hypertension but that only one-quarter are aware of their condition. ${ }^{1}$ Hypertension is the most powerful risk factor for cardiovascular disease. $^{2}$ In addition, increased blood pressure is the leading preventable risk factor for premature mortality in the general population in China. ${ }^{3}$ Despite increased rates of blood pressure-lowering treatment, only a few patients have their hypertension effectively controlled. ${ }^{4}$ The economic burden of hypertension is heavy due to both direct healthcare costs and indirect costs from the cardiocerebral vascular complications.

Clinical practice guidelines (CPGs) for hypertension have been developed to help optimise the management of the condition and are thought to be capable of improving the quality, appropriateness and costeffectiveness of patient care. ${ }^{5}$ The intention of CPGs is to reduce the gap between research and practice, and to provide professionals with recommendations based on the best currently available evidence on how to manage health conditions. ${ }^{6}{ }^{7}$ The use of CPGs is recognised as an important component of hypertension management, including support for the use of interventions that are 
of proven benefit and enhanced awareness of ineffective methods. However, a large number of practice guidelines have been produced by numerous organisations in China over the past 10 years, and the increasing interest in the development of CGPs for hypertension has been accompanied by growing concerns about the variations in the recommendations and qualities among the guidelines. ${ }^{8-10}$ The methodological quality is of great importance, and it is thus critical to assess CPGs for hypertension using a well-defined process. A high methodological quality CPG development process is more likely to yield a CPG that contains relevant and appropriate recommendations. ${ }^{11}$

Several guideline appraisal tools have been developed to assess the methodological quality of guidelines. ${ }^{12}$ The Appraisal of Guidelines for REsearch \& Evaluation (AGREE) Instrument, developed by an international group of researchers from 13 countries, has been validated and accepted to address the issue of variability and to appraise the methodological quality of CPGs. ${ }^{13-15}$ The original AGREE Instrument, which was released in 2003, has been refined to improve the usability and methodological properties, which resulted in the AGREE II reported in 2009. ${ }^{16}$ The AGREE II instrument is valid and reliable, with a 23-item tool comprising six quality domains, followed by 2 final overall assessment items that require the appraiser to make overall judgments of the CPGs and to reflect on the development process. The aim of the present systematic review was to evaluate the methodological quality of CPGs for hypertension, developed in China, using the AGREE II instrument.

\section{METHODS}

\section{Search strategy}

According to a prespecified search strategy, relevant guidelines were identified through searches of the CBM (Chinese Biomedical Literature Database), Wanfang Database, CNKI (Chinese National Knowledge Infrastructure) and CGC (China Guideline Clearinghouse) websites up to March 2014. Reference lists of all relevant guidelines were manually scanned and, in addition, Google Scholar was searched for additional information.

We employed a combined search of MeSH terms and free-text words, and the following search terms, "hypertension" or "high blood pressure" and "guideline" or "recommendation" or "consensus", were used. Two investigators independently screened the titles and abstracts of the literature for potentially relevant guidelines.

\section{Inclusion and exclusion criteria}

All CPGs developed in China about the management of hypertension in adult patients were eligible for inclusion in the present study. Single-author overviews, secondary or multiple publications, editorials, translations and short summaries, were specifically excluded. The latest version of the guideline was identified for assessment and, if several publication forms of one guideline existed, only the form that included the greatest detail on the methodology used for the guideline development was assessed.

\section{Quality assessment}

The methodological quality of existing CPGs for hypertension was evaluated using the AGREE II instrument, which consists of 23 items organised within six domains: scope and purpose, stakeholder involvement, rigor of development, clarity of presentation, applicability and editorial independence.

When using this instrument, each item is ranked on a 7-point scale ranging from 1 (strongly disagree) to 7 (strongly agree). A score of 1 is given when there is no information on that item or if it is poorly reported. A score of 7 is given if the quality of reporting is excellent and when full criteria have been met.

The score for each domain is obtained by adding together all of the scores of the individual items in a domain and then standardising them as follows:

\section{Obtained score - Minimum possible score}

Maximum possible score - Minimum possible score

Although using a single quality score is not encouraged by the AGREE II, an overall assessment is included. The final component of the AGREE II instrument involves a recommendation regarding the use of the guidelines in practice as "Yes, to recommend this guideline $(\mathrm{Y})$ "; "Yes, to recommend but with modification (Y, but)" and "No, not to recommend (N)". For each guideline that was given a recommendation of $(\mathrm{Y})$, the overall domain scores were $\geq 60 \%$ for all six domains. For guidelines that were given a recommendation of $(\mathrm{N})$, the overall domain scores were $<30 \%$ for at least three domains. For the guidelines that were given a recommendation of (Y, but), the overall domain scores were $\geq 30 \%$ for at least three domains, while at least one domain had a score of $<60 \% .^{17} 18$

Two investigators with a full understanding of the AGREE II manual independently assessed the identified CPGs. Prior to evaluating the guidelines included in the review, each investigator rated a superseded guideline, and then the rates were compared among reviewers, discrepancies were discussed, and a consensus was reached about the interpretation of each question. ${ }^{19}$ The $\kappa$ score was adopted as a measure of the agreement between the two appraisers' ordinal item assessment (strongly agree/ agree vs strongly disagree/disagree). Although there are no absolute cut-offs for interpreting $\kappa$ coefficients, a $\kappa>0.8$ is generally considered to be acceptable. ${ }^{2021}$

\section{RESULTS}

\section{Search and description of studies}

A total of 7845 articles were identified, 101 of which were considered to be potentially relevant and 17 of which proved eligible for final evaluation, as summarised in figure 1. The general characteristics of the assessed 


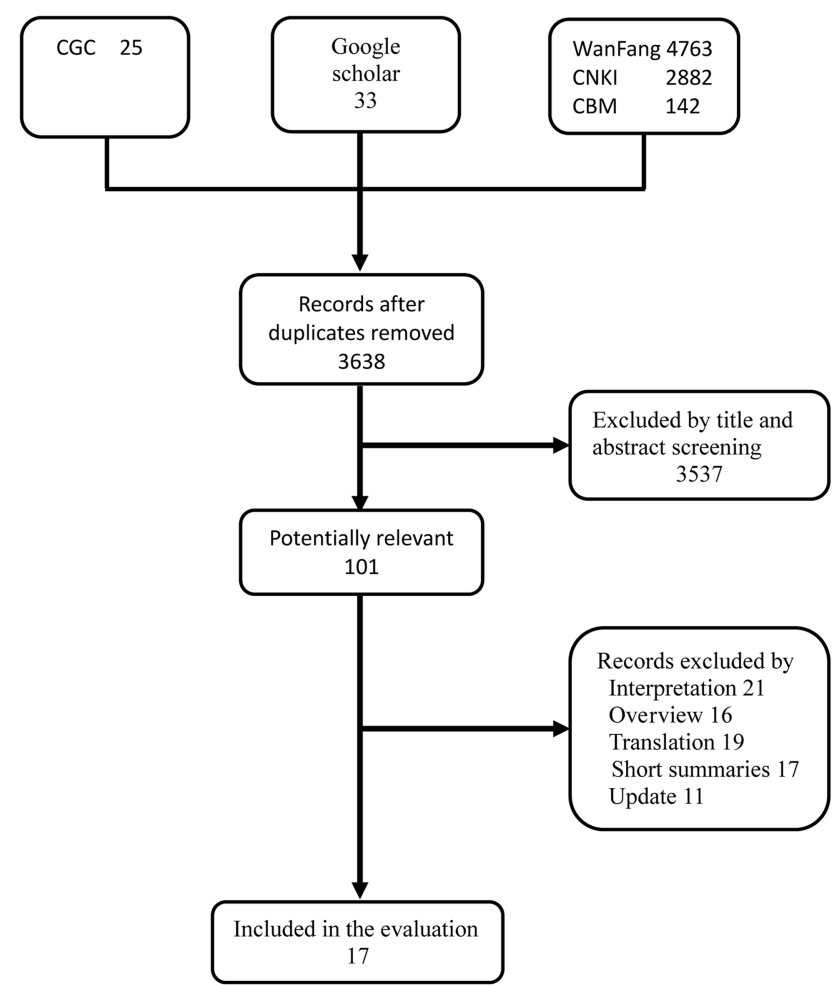

Figure 1 Flow diagram of guideline selection (CBM, Chinese Biomedical Literature Database; CGC, China Guideline Clearinghouse; CNKI, Chinese National Knowledge Infrastructure).

guidelines are shown in table $1 .^{22-38}$ The publication dates ranged from 2001 to 2011. The number of references cited ranged from 0 to 218, with five guidelines not reporting any references, ${ }^{26} 31343538$ four of which were developed on the Chinese mainland. ${ }^{31} 343538$ The majority of the reviewed CPGs (13 guidelines) were published in Chinese, while four guidelines were published in English, ${ }^{26-28} 37$ two of which were developed in Hong Kong $^{26} 37$ and two in Taiwan. ${ }^{27} 28$ A total of four $\mathrm{CPGs}^{23} 293336$ stated that they received drug company sponsorship, but only one of these guidelines declared that the views of the funding bodies did not influence the recommendations, and a declaration of the conflicts of interest of the guideline developers was not provided for 13 CPGs.

Six of the 17 CPGs assessed covered the management of hypertension in general, ${ }^{23}$ 25-28 37 with 1 focused on prevention $^{28}$ and 1 focused on emergency hypertension. ${ }^{25}$ The others were specific to the pharmaceutical treatment of hypertension, one of which concerned Traditional Chinese medicine, ${ }^{32}$ one ethnomedicine, ${ }^{31}$ one the elderly, ${ }^{33}$ and one, home medication. ${ }^{38}$

The majority of CPGs did not describe the level of evidence they cited or grade the recommendations. Two guidelines developed on the Chinese mainland coded the level of evidence (I, IIa/IIb, III) on the basis of the study design, without linking these codes to the recommendations (A, B, C). ${ }^{29}$ Only one guideline developed in Hong Kong classified the level of evidence and explicitly linked the evidence to the recommendations using the Scottish Intercollegiate Guidelines Network (SIGN) classification. ${ }^{26}$

\section{Guideline quality scores}

The scaled AGREE II domain percentages for all 17 CPGs are presented in table 2. Concerning the 'scope and purpose' and 'clarity of presentation' of the guidelines, the mean score for both was $41 \%$, with a range of $6-78 \%$ and $6-67 \%$, respectively. These two domains were the most adequately addressed, with scores above $60 \%$ in 4 of the 17 clinical guidelines.

Less well addressed was the 'stakeholder involvement' domain, for which the average domain score was $28 \%$, with the extremes being 3-67\%, and only 1 of the 17 guidelines scored above $60 \%$. CPGs performed similarly in the domain of 'applicability', with one scoring above $60 \%$, while the average score was $20 \%$ and varied from $0 \%$ to $69 \%$, including one CPG that scored $0 \%$.

The last two domains were the least well addressed. On average, the score for the 'rigor of development' domain was $18 \%$, with scores ranging between $1 \%$ and $36 \%$. Finally, the scores for the 'editorial independence' domain ranged from $0 \%$ to $46 \%$, with an average domain score of $16 \%$, including five CPGs that scored $0 \%$, making this domain the least well addressed.

The final evaluation of the guidelines summarises the overall opinion of whether or not the guideline should be recommended for clinical use. Eight out of the 17 CPGs can be recommended, with modification, for use based on the AGREE II instrument.

\section{DISCUSSION}

There has been an increase in the development of CPGs in the field of hypertension; however, to the best of the authors' knowledge, the present systematic review is the first attempt to evaluate the methodological quality of CPGs for the management of hypertension in China using the AGREE II instrument. It should be noted that the AGREE II instrument reflects how well the development process is reported but does not assess the content of the CPG or the quality of evidence used to formulate the recommendations, which is a common deficit of all existing appraisal tools. ${ }^{12}$

We found that there was considerable variation in the assessed CPGs in terms of the number of pages, authors and references. It was found that some CPGs comprised just one page, without any references or authors' names, and many CPGs did not provide a statement about any potential conflicts of interest. It has been stated that if a conflict of interest is unavoidable, it should be disclosed. For these guidelines with no declaration of the conflicts of interest, there may have been no conflicts, but because the authors did not state that there was 'no conflict of interest', the potential for conflict is unclear. A few CPGs described the level of evidence, but without 


\begin{tabular}{|c|c|c|c|c|c|c|c|c|}
\hline $\begin{array}{l}\text { Serial } \\
\text { number }\end{array}$ & Guidelines & $\begin{array}{l}\text { Publish } \\
\text { date }\end{array}$ & $\begin{array}{l}\text { Number } \\
\text { of pages }\end{array}$ & $\begin{array}{l}\text { Number } \\
\text { of authors }\end{array}$ & $\begin{array}{l}\text { Number of } \\
\text { references }\end{array}$ & Subject & Region & Organisation \\
\hline 1 & $\begin{array}{l}\text { Diuretics for hypertension: } \\
\text { Chinese experts' consensus }\end{array}$ & 2011 & 9 & 46 & 65 & Drug intervention & $\begin{array}{l}\text { Chinese } \\
\text { mainland }\end{array}$ & $\begin{array}{l}\text { The Subspecialty Group of Hypertension, } \\
\text { Society of Cardiology, Chinese Medical } \\
\text { Association }\end{array}$ \\
\hline 2 & $\begin{array}{l}2010 \text { Chinese guidelines for the } \\
\text { management of hypertension }{ }^{23}\end{array}$ & 2011 & 38 & 43 & 218 & $\begin{array}{l}\text { Comprehensive } \\
\text { management }\end{array}$ & $\begin{array}{l}\text { Chinese } \\
\text { mainland }\end{array}$ & $\begin{array}{l}\text { Writing Group of } 2010 \text { Chinese Guidelines } \\
\text { for the Management of Hypertension }\end{array}$ \\
\hline 3 & $\begin{array}{l}\text { Expert consensus on the clinical } \\
\text { application of levamlodipine } \\
\text { besylate }^{24}\end{array}$ & 2010 & 3 & 4 & 19 & Drug intervention & $\begin{array}{l}\text { Chinese } \\
\text { mainland }\end{array}$ & $\begin{array}{l}\text { Cardiovascular Medicine Branch of China } \\
\text { Medical Doctor Association; } \\
\text { Cardio-cerebrovascular Disease Branch of } \\
\text { Chinese Geriatrics Society }\end{array}$ \\
\hline 4 & $\begin{array}{l}\text { Expert consensus on diagnostic } \\
\text { and treatment of Chinese } \\
\text { emergency hypertension }{ }^{25}\end{array}$ & 2010 & 12 & $U$ & 35 & $\begin{array}{l}\text { Emergency } \\
\text { hypertension }\end{array}$ & $\begin{array}{l}\text { Chinese } \\
\text { mainland }\end{array}$ & $\begin{array}{l}\text { Emergency Physicians Branch of Chinese } \\
\text { Medical Doctor Association }\end{array}$ \\
\hline 5 & $\begin{array}{l}\text { Hong Kong reference framework } \\
\text { for hypertension care for adults in } \\
\text { primary care settings }{ }^{26}\end{array}$ & 2010 & 40 & 82 & 0 & $\begin{array}{l}\text { Comprehensive } \\
\text { management }\end{array}$ & $\begin{array}{l}\text { Hong Kong, } \\
\text { China }\end{array}$ & $\begin{array}{l}\text { Task Force on Conceptual Model and } \\
\text { Preventive Protocols Working Group on } \\
\text { Primary Care; Food and Health Bureau }\end{array}$ \\
\hline 6 & $\begin{array}{l}2010 \text { Guidelines of the Taiwan } \\
\text { Society of Cardiology for the } \\
\text { management of hypertension }\end{array}$ & 2010 & 34 & 12 & 208 & $\begin{array}{l}\text { Comprehensive } \\
\text { management }\end{array}$ & $\begin{array}{l}\text { Taiwan, } \\
\text { China }\end{array}$ & $\begin{array}{l}\text { Hypertension Committee of the Taiwan } \\
\text { Society of Cardiology }\end{array}$ \\
\hline 7 & $\begin{array}{l}\text { Guidelines for the management of } \\
\text { hypertension. Taiwan stroke } \\
\text { association }^{28}\end{array}$ & 2010 & 8 & 15 & $U$ & $\begin{array}{l}\text { Comprehensive } \\
\text { management }\end{array}$ & $\begin{array}{l}\text { Taiwan, } \\
\text { China }\end{array}$ & Taiwan Stroke Association \\
\hline 8 & $\begin{array}{l}\beta \text {-Blocker in the management of } \\
\text { cardiovascular diseases: an expert }^{\text {announcement }^{29}}\end{array}$ & 2009 & 23 & 18 & 70 & Drug intervention & $\begin{array}{l}\text { Chinese } \\
\text { mainland }\end{array}$ & $\begin{array}{l}\text { Chinese Society of Cardiology of Chinese } \\
\text { Medical Association; Editorial Board of } \\
\text { Chinese Journal of Cardiology }\end{array}$ \\
\hline 9 & $\begin{array}{l}\text { Expert consensus on the } \beta \text {-blocker } \\
\text { for the treatment of hypertension }{ }^{30}\end{array}$ & 2008 & 4 & 23 & 70 & Drug intervention & $\begin{array}{l}\text { Chinese } \\
\text { mainland }\end{array}$ & $\begin{array}{l}\text { The Chinese Medical Doctor Association, } \\
\text { Evidence-Based Medicine Professional } \\
\text { Committee }\end{array}$ \\
\hline 10 & $\begin{array}{l}\text { Uyghur diagnosis and treatment } \\
\text { guidelines for hypertension }{ }^{31}\end{array}$ & 2008 & 1 & 5 & 0 & Ethno medicine & $\begin{array}{l}\text { Chinese } \\
\text { mainland }\end{array}$ & Uyghur Medical Hospital \\
\hline 11 & $\begin{array}{l}\text { Traditional Chinese medicine for } \\
\text { hypertension (first draft) }\end{array}$ & 2008 & 3 & 1 & 33 & $\begin{array}{l}\text { Traditional } \\
\text { Chinese medicine }\end{array}$ & $\begin{array}{l}\text { Chinese } \\
\text { mainland }\end{array}$ & $\begin{array}{l}\text { Cardiology Branch of China Association of } \\
\text { Chinese Traditional Medicine }\end{array}$ \\
\hline 12 & $\begin{array}{l}\text { Expert consensus on hypertension } \\
\text { in the elderly in China }{ }^{33}\end{array}$ & 2008 & 9 & 77 & 52 & Elderly people & $\begin{array}{l}\text { Chinese } \\
\text { mainland }\end{array}$ & $\begin{array}{l}\text { Chinese Elderly Hypertension Treatment } \\
\text { Consensus Committee }\end{array}$ \\
\hline 13 & $\begin{array}{l}\text { Expert consensus on long-term } \\
\text { two hydrogen pyridine calcium } \\
\text { channel blockers for chronic renal } \\
\text { hypertension }\end{array}$ & 2008 & 1 & $U$ & 0 & Drug intervention & $\begin{array}{l}\text { Chinese } \\
\text { mainland }\end{array}$ & $\begin{array}{l}\text { Kidney Diseases Branch of the Chinese } \\
\text { Medical Association }\end{array}$ \\
\hline 14 & $\begin{array}{l}\text { Expert consensus on the clinical } \\
\text { application of the new fixed-dose } \\
\text { combinations of } A R B / H C T Z^{35}\end{array}$ & 2007 & 3 & 18 & 0 & Drug intervention & $\begin{array}{l}\text { Chinese } \\
\text { mainland }\end{array}$ & $\begin{array}{l}\text { "The new fixed-dose combinations of ARB/ } \\
\text { HCTZ" Expert Group }\end{array}$ \\
\hline 15 & $\begin{array}{l}\text { Angiotensin converting enzyme } \\
\text { inhibitor in the management of } \\
\text { cardiovascular diseases: a } \\
\text { Chinese expert announcement }{ }^{36} \\
\end{array}$ & 2007 & 10 & 42 & 65 & Drug intervention & $\begin{array}{l}\text { Chinese } \\
\text { mainland }\end{array}$ & $\begin{array}{l}\text { Chinese Society of Cardiology of Chinese } \\
\text { Medical Association; Editorial Board of } \\
\text { Chinese Journal of Cardiology }\end{array}$ \\
\hline
\end{tabular}

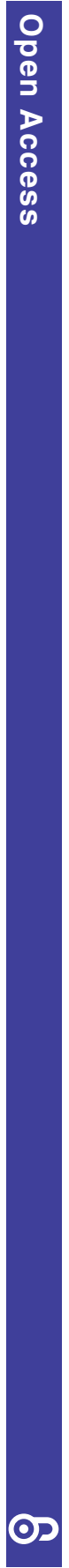

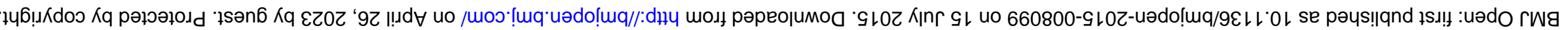




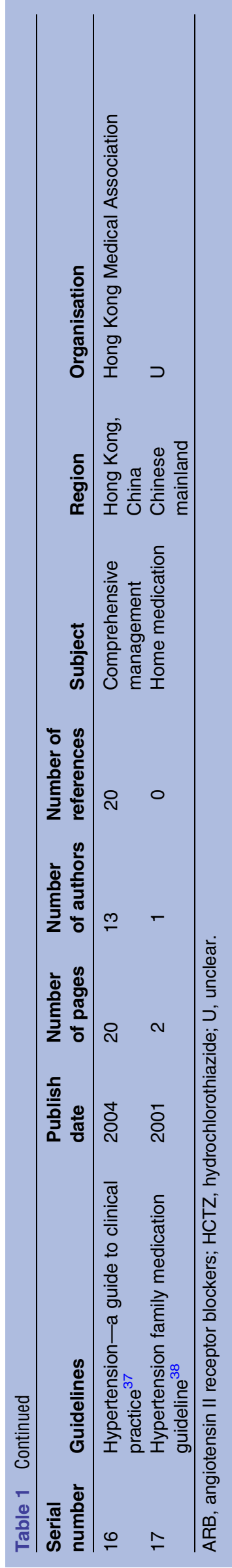

linking it to the recommendations. The differences and shortcomings in the classification and grading system were confusing.

Our results demonstrated that the methodological quality of CPGs for hypertension is undesirable in general and varies from guideline to guideline according to the different domains, with the "clarity of presentation' and 'scope and purpose' receiving the highest scores, the 'rigor of development' and 'editorial independence' scoring the lowest, and 'stakeholder involvement' and 'applicability' being between these domains. The assessed guidelines performed best in the domains of 'clarity of presentation' and 'scope and purpose', which was consistent with the findings of a systematic review for recent hypertension CPGs, ${ }^{39}$ five priority diseases' CPGs within Southern Africa ${ }^{40}$ and endocrine CPGs in North America. ${ }^{41}$ Despite the fact that these two domains scored highest among the six, the scores were still much lower than the global average scores, and great improvements that include clearly summarising and focusing on the issues that are most related to the patients and physicians are needed in the future in China. ${ }^{42}$

The CPGs for hypertension developed by the Writing Group of 2010, Chinese Guidelines for the Management of Hypertension in 2010, received the highest scores on average, but these were generally still less than $60 \%$. Further assessment indicated that it failed to provide sufficient details about how the final recommendations were formulated.

The most poorly undertaken domain, 'editorial independence', is meant to assess the possible conflicts of interest of the author(s) and whether the guideline was developed independently of the funding source. European guidelines on a range of topics published from 2000 to 2007 similarly found that most guidelines scored low on 'editorial independence', ${ }^{43}$ while hypertension CPGs published from 2006 to 2011 confirmed that great progress had been made in the 'editorial independence' domain. ${ }^{39}$ Poor scores for hypertension CPGs developed in China highlight the need to improve the development process under an explicit conflict of interest. Insight into the 'editorial independence' increases the transparency of the guideline development process. The cited reasons for the low scores included poor reporting on whether a conflict of interest was assessed during the process of development of the guidelines or, if it was assessed, how it was addressed. ${ }^{44}$ However, low scores can also be explained by poor reporting. When no information is provided about the assessment item, the corresponding score will be low, which may not mean that the guideline was inappropriately developed, but that there was inadequate information provided.

All of the guidelines performed poorly with respect to 'rigor of development', which is considered to be crucial for the guideline quality by ensuring that a rigorous process was used to judge the underlying quality of evidence on which the guidelines were developed. A 
Table 2 AGREE scores of the included guidelines

\begin{tabular}{|c|c|c|c|c|c|c|c|}
\hline \multirow[b]{2}{*}{$\begin{array}{l}\text { Serial } \\
\text { number of } \\
\text { guidelines }\end{array}$} & \multicolumn{6}{|l|}{ Score (\%) } & \multirow[b]{2}{*}{$\begin{array}{l}\text { Overall } \\
\text { assessment }\end{array}$} \\
\hline & $\begin{array}{l}\text { Scope } \\
\text { and } \\
\text { purpose }\end{array}$ & $\begin{array}{l}\text { Stakeholder } \\
\text { involvement }\end{array}$ & $\begin{array}{l}\text { Rigour of } \\
\text { development }\end{array}$ & $\begin{array}{l}\text { Clarity of } \\
\text { presentation }\end{array}$ & Applicability & $\begin{array}{l}\text { Editorial } \\
\text { independence }\end{array}$ & \\
\hline 1 & 14 & 25 & 20 & 44 & 6 & 13 & $\mathrm{~N}$ \\
\hline 2 & 50 & 56 & 25 & 64 & 69 & 46 & $\mathrm{Y}$, but \\
\hline 3 & 19 & 22 & 15 & 42 & 10 & 17 & $N$ \\
\hline 4 & 67 & 22 & 19 & 45 & 21 & 13 & $\mathrm{Y}$, but \\
\hline 5 & 61 & 67 & 35 & 42 & 42 & 13 & $\mathrm{Y}$, but \\
\hline 6 & 28 & 39 & 36 & 36 & 17 & 17 & $\mathrm{~N}$ \\
\hline 7 & 58 & 36 & 28 & 67 & 17 & 33 & $\mathrm{Y}$, but \\
\hline 8 & 50 & 14 & 34 & 64 & 25 & 29 & $\mathrm{Y}$, but \\
\hline 9 & 39 & 36 & 11 & 61 & 17 & 13 & $\mathrm{~N}$ \\
\hline 10 & 6 & 3 & 1 & 6 & 0 & 0 & $\mathrm{~N}$ \\
\hline 11 & 11 & 11 & 7 & 8 & 4 & 0 & $\mathrm{~N}$ \\
\hline 12 & 44 & 28 & 11 & 28 & 38 & 21 & $\mathrm{~N}$ \\
\hline 13 & 33 & 8 & 7 & 22 & 15 & 0 & $\mathrm{~N}$ \\
\hline 14 & 64 & 19 & 5 & 42 & 17 & 0 & $\mathrm{~N}$ \\
\hline 15 & 78 & 36 & 30 & 56 & 17 & 17 & Y, but \\
\hline 16 & 58 & 47 & 27 & 56 & 27 & 33 & $\mathrm{Y}$, but \\
\hline 17 & 11 & 3 & 2 & 17 & 4 & 0 & $\mathrm{~N}$ \\
\hline Total & $41 \pm 23$ & $28 \pm 18$ & $18 \pm 12$ & $41 \pm 19$ & $20 \pm 17$ & $16 \pm 14$ & $\begin{array}{l}Y \text {, but (8) } \\
\mathrm{N}(9)\end{array}$ \\
\hline
\end{tabular}

further analysis found that seven CPGs with the name of 'expert consensus' scored 12\% (ranging from 5\% to $20 \%$ ), which is less than the average level, indicating that the scores for the domain of 'rigor of development' could be considered a useful reference to differentiate consensus from guideline. This step can play a key role in determining whether the recommendations are truly based on the evidence and in understanding how the evidence is synthesised. There is an explicit link between the best evidence available and the recommendations made, including clarifying which systems were used to evaluate the quality of the evidence and to grade recommendations. ${ }^{45}$

The less well addressed domain, 'applicability', produced disagreement, with the findings of the most recent published studies reporting that 'applicability' domain scored $(42 \%)$ lower than the other five AGREE domains among 137 guidelines developed in USA, Canada, UK and an international group. ${ }^{46}$ Coming to the hypertension CPGs, 'applicability' scored low (38\%) relative to all domains but 'rigor of development' $(30 \%) .{ }^{39}$ It was shown that the type of developer (disease-specific foundation, non-profit healthcare system) was associated with applicability score, and the majority of hypertension CPGs included in the present study was developed by hypertension-specific association and non-profit healthcare system, which may be explained by the applicability scores achieved. Although the reported 'applicability' domain performed poorly, the scores are much higher than the score in the present study. The poor 'applicability' scores reflected that the implementation of guidelines, such as organisation barriers, the cost and the criteria used to monitor the local implementation or adaption, were not clearly addressed. ${ }^{47} 48$ It is worth considering that the process of defining facilitators and barriers to application should be integrated early in the guideline development process, including professional implementation strategies. ${ }^{49}$

The assessed guidelines achieved a moderate mean score in the 'stakeholder involvement' domain, which assessed the degree to which the guideline represents the views of its intended audience. ${ }^{50}$ It could be noted that patient preferences and experiences should be factored into decisions regarding clinical care, especially hypertension, the management of which can impact quality of life. The guidelines we reviewed would have benefited from ensuring that all guideline committees had patient representatives and that literature reviews specifically addressed the quality of life (when available).

The main limitation of this study is that the methodological quality assessment was based on what the CPGs developers actually reported, which might not truly reflect the construction process. Although two independent trained appraisers conducted the assessment using a standardised instrument, the involvement of subjective bias in the evaluation was unavoidable. The AGREE collaboration recommends that each guideline be assessed by at least two appraisers, but that without proper training, adding appraisers may increase the rating bias. ${ }^{51}$ 


\section{CONCLUSION}

The overall methodological quality of the CPGs for hypertension in China was generally low throughout the appraisal process as determined using the AGREE II instrument. Considerable variability remained between guidelines, and strategies should be implemented to enhance the clarification of the subject of CPGs, the application of evidence-based systematic methods, and the transparency of CPGs. In addition, multidisciplinary groups associated with professional organisations in China, especially the methodological experts in the field for which the CPG is being drawn up, should be consulted.

Acknowledgements The authors would like to thank Boxi Yan at West China Medical School, West China Hospital of Sichuan University, for his kind and insightful suggestions in the review.

Contributors $Y C$ and $\mathrm{SH}$ contributed in the conception and design. YC, LW and XF participated in the searching for and extracting the data. YC, LW, XF, $W X$ and GS were involved in assessing and analysing the quality of the guideline. YC participated in the writing the manuscript. SH, WX and GS provided administrative and technical support.

Funding This research received no specific grant from any funding agency in the public, commercial or not-for-profit sectors.

Competing interests None declared.

Provenance and peer review Not commissioned; externally peer reviewed.

Data sharing statement No additional data are available.

Open Access This is an Open Access article distributed in accordance with the Creative Commons Attribution Non Commercial (CC BY-NC 4.0) license, which permits others to distribute, remix, adapt, build upon this work noncommercially, and license their derivative works on different terms, provided the original work is properly cited and the use is non-commercial. See: http:// creativecommons.org/licenses/by-nc/4.0/

\section{REFERENCES}

1. Wu Y, Huxley R, Li L, et al, China NNHS Steering Committee; China NNHS Working Group. Prevalence, awareness, treatment, and control of hypertension in China: data from the China National Nutrition and Health Survey 2002. Circulation 2008;118:2679-86.

2. Gu D, Kelly TN, Wu X, et al. Blood pressure and risk of cardiovascular disease in Chinese men and women. $A m \mathrm{~J}$ Hypertens 2008;21:265-72.

3. He J, Gu D, Chen J, et al. Premature deaths attributable to blood pressure in China: a prospective cohort study. Lancet 2009;374:1765-72.

4. Kearney PM, Whelton M, Reynolds K, et al. Global burden of hypertension: analysis of worldwide data. Lancet 2005;365:217-23.

5. Field MJ, Lohr KN, eds, Institute of Medicine Committee to Advise the Public Health Service on Clinical Practice Guidelines. Clinical practice guidelines: directions for a new program. Washington DC: National Academy Press, 1990.

6. Grimshaw JM, Russell IT. Effect of clinical guidelines on medical practice: a systematic review of rigorous evaluations. Lancet 1993;342:1317-22.

7. McAlister FA, van Diepen S, Padwal RS, et al. How evidence-based are the recommendations in evidence-based guidelines? PLoS Med 2007; 4:e250.

8. Shaneyfelt TM, Mayo-Smith MF, Rothwangl J. Are guidelines following guidelines? The methodological quality of clinical practice guidelines in the peer-reviewed medical literature. JAMA 1999;281:1900-5.

9. Lacasse Y, Ferreira I, Brooks D, et al. Critical appraisal of clinical practice guidelines targeting chronic obstructive pulmonary disease. Arch Intern Med 2001;161:69-74.

10. Cluzeau FA, Littlejohns P, Grimshaw JM, et al. Development and application of a generic methodology to assess the quality of clinical guidelines. Int J Qual Health Care 1999;11:21-8.
11. Turner T, Misso M, Harris C, et al. Development of evidence-based clinical practice guidelines (CPGs): comparing approaches. Implement Sci 2008;3:45.

12. Vlayen J, Aertgeerts B, Hannes $\mathrm{K}$, et al. A systematic review of appraisal tools for clinical practice guidelines: multiple similarities and one common deficit. Int J Qual Health Care 2005;17:235-42.

13. The AGREE Collaboration. Development and validation of an international appraisal instrument for assessing the quality of clinical practice guidelines: the AGREE project. Qual Safe Health Care 2003;12:18-23.

14. Brouwers MC, Kho ME, Browman GP, et al., AGREE Next Steps Consortium. AGREE II: advancing guideline development, reporting and evaluation in healthcare. CMAJ 2010;182:E839-42.

15. Schünemann HJ, Hill SR, Kakad M, et al. Transparent development of the WHO rapid advice guidelines. PLoS Med 2007;4:e119.

16. AGREE Next Steps Consortium. The AGREE II Instrument [Electronic version]. 2009. Retrieved 15 May 2013, http://www. agreetrust.org

17. Lopez-Olivo MA, Kallen MA, Ortiz Z, et al. Quality appraisal of clinical practice guidelines and consensus statements on the use of biologic agents in rheumatoid arthritis: a systematic review. Arthritis Rheum 2008;59:1625-38.

18. Hu J, Chen R, Wu S, et al. The quality of clinical practice guidelines in China: a systematic assessment. J Eval Clin Pract 2013;19:961-7.

19. Ettinger DS, Cox JD, Ginsberg RJ, et al. NCCN Non-Small-Cell Lung Cancer Practice Guidelines: the National Comprehensive Cancer Network. Oncology (Williston Park) 1996;10:81-111.

20. Landis JR, Koch GG. An application of hierarchical kappa-type statistics in the assessment of majority agreement among multiple observers. Biometrics 1977;33:363-74.

21. Landis JR, Koch GG. The measurement of observer agreement for categorical data. Biometrics 1977;33:159-74.

22. The Subspecialty Group of Hypertension, Society of Cardiology, Chinese Medical Association. Diuretics for hypertension: Chinese experts' consensus. Chin J Hypertens 2011;19:214-22.

23. Liu LS, Writing Group of 2010 Chinese Guidelines for the Management of Hypertension. [2010 Chinese guidelines for the management of hypertension]. Chin J Cardiol 2011;39:579-615.

24. Cardiovascular Medicine Branch of China Medical Doctor Association; Cardio-cerebrovascular Disease Branch of Chinese Geriatrics Society. Expert consensus on the clinical application of levamlodipine besylate. Chin J Intern Med 2010;49:987-9.

25. Emergency Physicians Branch of Chinese Medical Doctor Association. Expert consensus on diagnostic and treatment of Chinese emergency hypertension. Chin J Crit Care 2010;30:865-76.

26. Task Force on Conceptual Model and Preventive Protocols; Working Group on Primary Care; Food and Health Bureau. Hong Kong reference framework for hypertension care for adults in primary care settings. 2010. http://www.pco.gov.hk/english/resource/ professionals hypertension pdf.htm

27. Chiang CE, Wang TD, $\mathrm{Li} \mathrm{YH}$, et al., Hypertension Committee of the Taiwan Society of Cardiology. 2010 Guidelines of the Taiwan Society of Cardiology for the management of hypertension. $J$ Formos Med Assoc 2010;109:740-73.

28. Lu YQ, Lin QH, Weng WZ, et al. Guidelines for the management of hypertension. Taiwan Stroke Association. Chin J Stroke 2010;5:558-62.

29. Chinese Society of Cardiology of Chinese Medical Association; Editorial Board of Chinese Journal of Cardiology. $\beta$-Blocker in the management of cardiovascular diseases: an expert announcement. 2009.

30. The Chinese Medical Doctor Association, Evidence-Based Medicine Professional Committee. Expert consensus on the $\beta$-blocker for the treatment of hypertension. Prev Treat Cardio Cereb Vasc Dis 2008;8:147-50.

31. Memet-Hasmu S, Srap A, Ahmat M, et al. Uyghur diagnosis and treatment guidelines for hypertension. J Med Pharma Chin Mino 2008;8:59.

32. Han XJ. Traditional Chinese medicine for hypertension (first draft). CJTCMP 2008;23:611-13.

33. Chinese Elderly Hypertension Treatment Consensus Committee. Expert consensus on hypertension in the elderly in China. Chin $J$ Geriatr Heart Brain Vessel Dis 2008;10:641-9.

34. Kidney Diseases Branch of the Chinese Medical Association. Expert consensus on long-term two hydrogen pyridine calcium channel blockers for chronic renal hypertension. Chin Med New 2008;23:22.

35. Zhang WZ. Expert consensus on the clinical application of the new fixed-dose combinations of ARB/HCTZ. Chin J Hypertens 2007;15:23-5.

36. Chinese Society of Cardiology of Chinese Medical Association; Editorial Board of Chinese Journal of Cardiology. Angiotensin converting enzyme inhibitor in the management of cardiovascular 
diseases: a Chinese expert announcement. Chin J Cardiol 2007;35:97-106.

37. Wong Bun-lap B. Hypertension-a guide to clinical practice. HKMA CME BULLETIN 2004;20:1-20.

38. He WS. Hypertension family medication guideline. Shou Du Yi Yao 2001;8:58-9.

39. Al-Ansary LA, Tricco AC, Adi $Y$, et al. A systematic review of clinical practice guidelines on the diagnosis, assessment and management of hypertension. PLOS ONE 2013;8:e53744.

40. Kredo T, Gerritsen A, van Heerden J, et al. Clinical practice guidelines within the Southern African Development Community: a descriptive study of the quality of guideline development and concordance with best evidence for five priority diseases. Health Res Policy Syst 2012;10:1

41. Bancos I, Cheng T, Prokop LJ, et al. Endocrine clinical practice guidelines in North America. A systematic assessment of quality. J Clin Epidemiol 2012;65:520-5.

42. Burgers J, Grol R, Klazinga N, et al. International comparison of 19 clinical guideline programs - a survey of the AGREE Collaboration. Z Arztl Fortbild Qualitatssich 2003;97:81-8.

43. Knai $C$, Brusamento $S$, Legido-Quigley $\mathrm{H}$, et al. Systematic review of the methodological quality of clinical guideline development for the management of chronic disease in Europe. Health Policy 2012;107:157-67.
44. Minhas R. Eminence-based guidelines: a quality assessment of the second Joint British Societies' guidelines on the prevention of cardiovascular disease. Int J Clin Pract 2007;61:1137-44.

45. Alonso-Coello $\mathrm{P}$, Irfan $\mathrm{A}$, Solà $\mathrm{I}$, et al. The quality of clinical practice guidelines over the last two decades: a systematic review of guideline appraisal studies. Qual Saf Health Care 2010;19:e58.

46. Gagliardi AR, Brouwers MC. Do guidelines offer implementation advice to target users? A systematic review of guideline applicability. BMJ Open 2015;5:e007047.

47. Fervers B, Burgers JS, Haugh MC, et al. Adaptation of clinical guidelines: literature review and proposition for a framework and procedure. Int J Qual Health Care 2006;18:167-76.

48. Fervers B, Burgers JS, Voellinger R, et al., ADAPTE Collaboration. Guideline adaptation: an approach to enhance efficiency in guideline development and improve utilisation. BMJ Qual Saf 2011;20:228-36.

49. Francke AL, Smit MC, de Veer AJ, et al. Factors influencing the implementation of clinical guidelines for health care professionals: a systematic meta-review. BMC Med Inform Decis Mak 2008;8:38.

50. Delgado-Noguera M, Tort S, Bonfill X, et al. Quality assessment of clinical practice guidelines for the prevention and treatment of childhood overweight and obesity. Eur J Pediatr 2009;168:789-99.

51. MacDermid JC, Brooks D, Solway S, et al. Reliability and validity of the AGREE instrument used by physical therapists in assessment of clinical practice guidelines. BMC Health Serv Res 2005;5:18. 